\title{
Investigation of Intermediate Compounds of Phenol in Photocatalysis Process
}

\author{
D. T. T. Trinh, S. T. T. Le, D. Channei, W. Khanitchaidecha, and A. Nakaruk
}

\begin{abstract}
Determining the degradation mechanism of phenol under illumination of titanium dioxide $\left(\mathrm{TiO}_{2}\right)$ is main task in this present work. The experiment carried out with $100 \mathrm{ppm}$ of phenol solution and $0.9 \mathrm{~g} / \mathrm{L} \mathrm{TiO}_{2}$ under UV-C light. The COD and UV-Vis measurement were applied in the present work to evaluate the efficiency of phenol removal. The results showed that photocatalysis removed effectively phenol from water after 24 hours of UV-C illumination. In the first 16 hours, there was a slight decrease in the COD value. However, it decreased dramatically after 24 hours of illumination. Similarly, the result from UV-Vis spectrophotometer also showed the same reduction of phenol peak. These proved that the photocatalytic degradation of phenol include two main phases. Phenol was transformed to by-products in the intermediate compound phase. Subsequently, these intermediate compoundss were removed from water under the form of carbon dioxide and water in the mineralization phase. Therefore, it is necessary to identify intermediate phase of phenol photodegradation in the further work.
\end{abstract}

Index Terms-Phenol, titanium dioixde, photodegradation, intermediate compounds.

\section{INTRODUCTION}

The presence of organic compounds in aqueous environment has caused several serious problems. Among recalcitrant organic compounds, phenol is considered generally to be one of the most toxic organic pollutants which cause several environmental problems [1]. The phenol pollution can come from various pollution sources such as paint, pesticides, coal conversion, polymeric resin, petroleum and petrochemical industries [2]. In aquatic environment, phenol is harmful to organisms at low concentration due to its toxicity, persistence and bioaccumulation. Additionally, it can also effect on human health, including fainting, vomiting, headache and paralysis, when people expose to phenol polluted water [3]. Additionally, potential carcinogenic compounds may be formed during disinfection and oxidation processes that cause health problem relating to mutation [4].

Manuscript received June 29, 2015; revised October 28, 2015.

D. T. T. Trinh and S. T. T. Le are with the Department of Civil Engineering, Naresuan Univesity, Thailand (e-mail: tttdang247@gmail.com janetle.176@gmail.com).

D. Channei is with Department of Chemistry, Faculty of Science, Naresuan University, Thailand (e-mail: duangdaoc@nu.ac.th).

W. Khanitchaidecha is with Department of Civil Engineering, Faculty of Engineering, Naresuan University, Thailand (e-mail: wilawank1@gmail.com).

A. Nakaruk is with Department of Industrial Engineering, Faculty of Engineering, Naresuan University, Thailand (e-mail: auppathamn@nu.ac.th).
Therefore, the phenol removal is a considered issue for current researches. In past decades, several technologies have been used and showed their efficiency in phenol removal. However, stabilization and solubility of phenol in water are obstacles in treatment processes. Conventional methods such as solvent extraction, activated carbon adsorption, common chemical oxidation, biodegradation and ion exchange have serious drawbacks including high cost or formation of hazardous by-products in phenol treatment [5]-[7]. Consequently, advanced oxidation processes (AOPs) are promising techniques to handle with phenol contaminated waters.

In recent years, AOPs are considered as optimum alternative methods that have received much attention in the phenol removal. The main principle of AOPs are based on using hydroxyl radicals $\left(\mathrm{OH}^{\circ}\right)$ which are known as one of the most powerful oxidizing species, these radicals oxidize strongly contaminants exist in water [8]. Among AOPs, the photocatalytic process using semiconductor catalysts has been demonstrated as an effective method in decomposing organic pollutants into biodegradable matters, and/or mineralizing completely to carbon dioxide $\left(\mathrm{CO}_{2}\right)$ and water $\left(\mathrm{H}_{2} \mathrm{O}\right)$ [9]. The basic mechanism of photocatalytic process is that semiconductor catalysts are excited under UV illumination leading to the movement of electrons from valence band to conduction band. This results in the formation of electron-hole pairs at the surface of catalyst. These electrons and holes continue to react with water and oxygen molecules to yield strongly oxidizing free radicals as $\mathrm{OH}^{\bullet}$ and superoxide species $\left(\mathrm{O}_{2}{ }^{\bullet}\right)$. The reactive agents then attack molecules of organic compounds in water and cause hydroxylation, oxidation, and mineralization in forming final products of carbon dioxide $\left(\mathrm{CO}_{2}\right)$ and water $\left(\mathrm{H}_{2} \mathrm{O}\right)$ [10], [11] Therefore, the semiconductor catalyst is an important part of photocatalytic process. Zinc oxide $(\mathrm{ZnO})$, cadmium sulfur (CdS), zinc sulfur $(\mathrm{ZnS})$, titanium dioxide $\left(\mathrm{TiO}_{2}\right)$, ferric oxide $\left(\mathrm{Fe}_{2} \mathrm{O}_{3}\right)$, gallium phosphide $(\mathrm{GaP})$ are typical semiconductor catalysts which often applied in photocatalytic process [12]. Among of them, titanium dioxide $\left(\mathrm{TiO}_{2}\right)$ is one of the most effective catalyst because its advantaged abilities such as non-photocorrosive, non-toxic, high oxidation and chemical stability [13], [14]. In addition In addition to these advantages, $\mathrm{TiO}_{2}$ catalyst has been proved to be the most active catalyst in earlier researches [15], [16].

Therefore, the aim of the present work was to investigate the photodegradation of phenol via chemical oxygen demand (COD) and UV-Vis measurement. In addition, the study also conducted experiment with different dosage of $\mathrm{TiO}_{2}$ to find the optimum concentration for phenol degradation. 


\section{MethodolOGY}

Photodegradation of phenol was carried out in batch reactor. $0.1 \mathrm{~g}$ of phenol solid was dissolved in $1 \mathrm{~L}$ of distilled water to make phenol solution. The present work used commercial $\mathrm{TiO}_{2}$ powder from Sigma-Aldrich as main catalyst in phenol photodegradation. The characteristic of $\mathrm{TiO}_{2}$ powder were described in the Table I [17].

TABLE I: SOME PRoperties OF COMMERCIAL TiO 2 PARTICLES

\begin{tabular}{cc}
\hline \hline Parameter & Value \\
\hline Anatase $(\%)$ & 95.97 \\
Rutile $(\%)$ & 4.03 \\
Particle size $(\mathrm{nm})$ & 400 \\
Specific surface area $\left(\mathrm{m}^{2} / \mathrm{g}\right)$ & 9.73 \\
Band gap $(\mathrm{eV})$ & 3.74 \\
\hline \hline
\end{tabular}

Beakers contained $50 \mathrm{~mL}$ of phenol solution with suspended $\mathrm{TiO}_{2}$ powders. In the present work, $215 \mathrm{~nm}$ of UV-C light was used to illuminate the suspended solution. Besides, magnetic stirrer operated with the rate of $100 \mathrm{rpm}$ to avoid the settling of $\mathrm{TiO}_{2}$ particles during photodegradation of phenol. Before measurement, the phenol solution containing $\mathrm{TiO}_{2}$ were centrifuged for $15 \mathrm{~min}$ at $5000 \mathrm{rpm}$.

The effect of catalyst concentration on photodegradation of phenol was examined to find out the optimum concentration by using different concentrations of $\mathrm{TiO}_{2}$ ranging from 0.01 to $2.00 \mathrm{~g} / \mathrm{L}$.

The optimal dosage of $\mathrm{TiO}_{2}$ was then used to degrade phenol solution under the following conditions: in the presence of UV light with and without $\mathrm{TiO}_{2}$, and in the combination of $\mathrm{TiO}_{2}$ and UV light.

The efficiency of phenol removal was evaluated via COD measurement by COD analyzer. Additionally, the present work also used UV-Vis spectroscopy (UV-6100 Double Beam Spectrophotometer) to measure the absorption of phenol solution. Basing on the measured spectrum, the degradation of phenol was evaluated through the absorbance peak at $270 \mathrm{~nm}[18]$.

\section{RESULTS AND DisCUSSION}

The removal efficiency of the concentration of $\mathrm{TiO}_{2}$ on phenol photodegradation is illustrated in Fig. 1. It clearly indicates that the degradation of phenol increases with increasing concentration of $\mathrm{TiO}_{2}$ and reaches optimal concentration at $0.9 \mathrm{~g} / \mathrm{L}$. On the other hands, the efficiency of phenol photodegradation is reduced slightly at higher concentration of catalyst (e.g., $2 \mathrm{~g} / \mathrm{L}$ ). The explanation of this phenomenon is that the penetration of light will be decreased by the suspension of catalyst at high concentration [19]. Therefore, the present work applied $0.9 \mathrm{~g} / \mathrm{L}$ of $\mathrm{TiO}_{2}$ concentration for further experiments.

Fig. 2 shows the degradation of phenol under different conditions as mentioned in the methodology section. The results indicated that phenol was only degraded under the combination of $\mathrm{TiO}_{2}$ and UV light. In the meantime, phenol was also absorbed around $5 \%$ on the surface of $\mathrm{TiO}_{2}$ particles. For only UV illumination, there is no any reaction occur over the time. This is because phenol contains a benzene ring which is known as the highly-stable structure resisting to decomposition reactions.

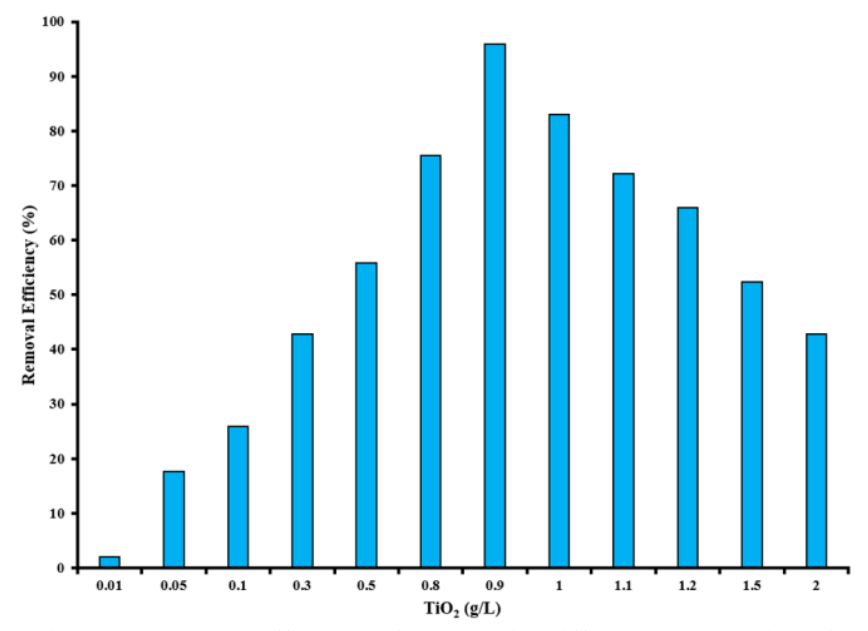

Fig. 1. The removal efficiency of phenol with different concentration of $\mathrm{TiO}_{2}$.

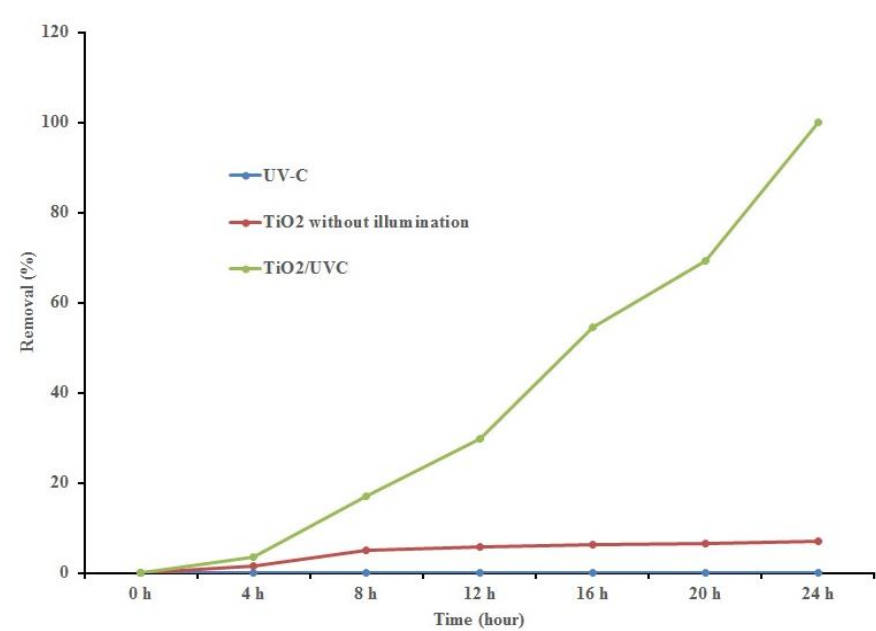

Fig. 2. Degradation of phenol under different conditions.

In the next step, the COD value was measured at every 2 hours, as shown in Fig. 3. The data shows that the COD value slightly decreased during the first 16 hours of illumination. This means that only a little phenol has been removed from water under the form of carbon dioxide $\left(\mathrm{CO}_{2}\right)$. However, the COD value reduced dramatically and reaches around $40 \mathrm{mg} / \mathrm{L}$ after 24 hours of illumination. This reveals that there are 2 phases in the photodegradation mechanism of phenol. The first phase is intermediate compound phase, in which phenol is degraded into intermediate products. After that, intermediate compounds continue to be oxidized and reach final products as carbon dioxide $\left(\mathrm{CO}_{2}\right)$ and water $\left(\mathrm{H}_{2} \mathrm{O}\right)$ in the mineralization phase.

The COD results are confirmed by UV-Vis measurement, as illustrated in Fig. 4. Similarly, the reduction mechanism of COD also occurred to the absorbance peak of phenol at 270 nm. For 16 hours of illumination, the phenol peak slowly decreased. However, it decreased quickly and disappears after 24 hours of illumination. It has to be noted that there are the presence of red shifts at around $300 \mathrm{~nm}$ of wavelength during photodegradation of phenol. The red shifts appeared only after 2 hours of illumination. It continued to increase until 12 hours of illumination, but there are the decreases of these shifts after 16 hours. These changes of red shifts proved more clearly that phenol underwent intermediate compounds phases before it was removed completely from water. 


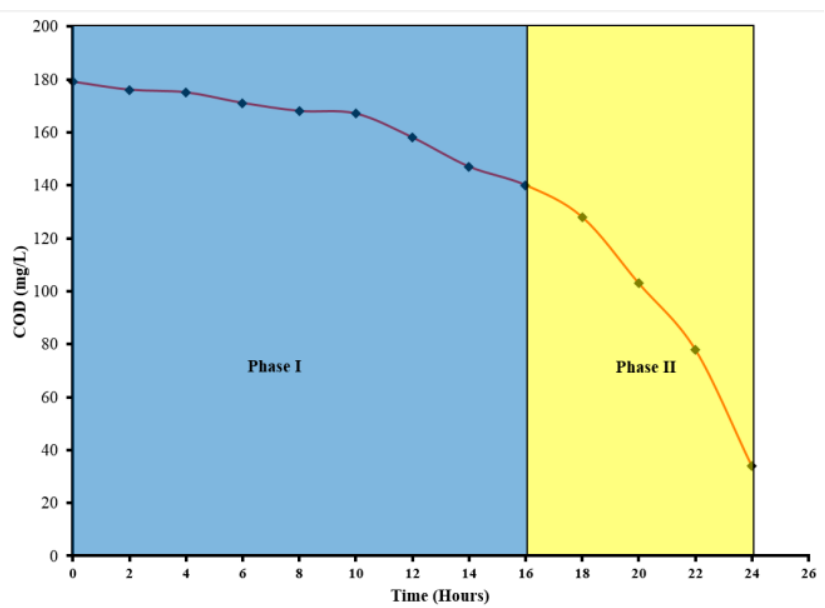

Fig. 3. The COD results of phenol solution at every 2 hours.

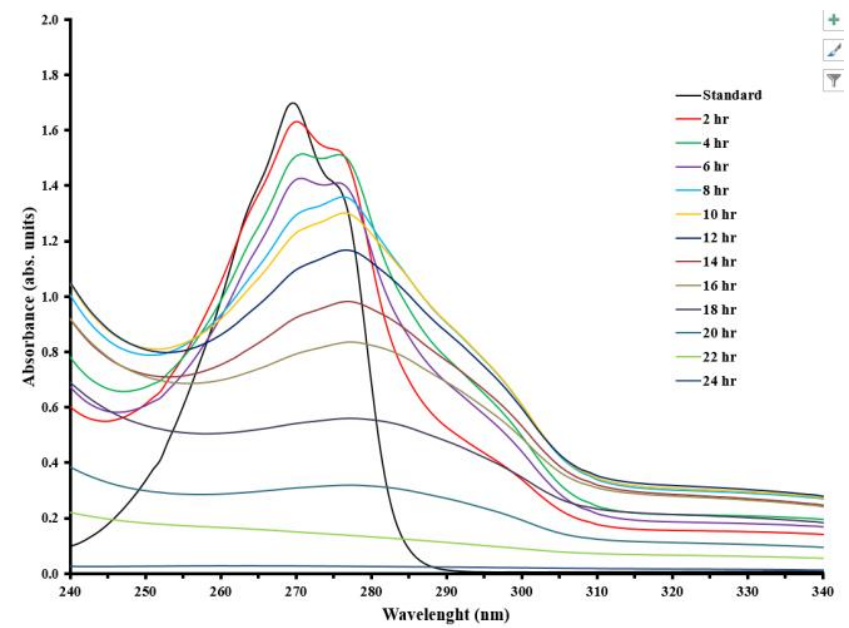

Fig. 4. The absorption spectrum of phenol at various illumination time.

These results reflected complex reaction mechanism in the degradation of phenol by photocatalysis using $\mathrm{TiO}_{2}$ catalyst that preliminarily reported in previous researches as shown in Fig. 5. This has contributed to prove that there are two main phases in the photodegradation mechanism of phenol including intermediate phase and mirelization phase.

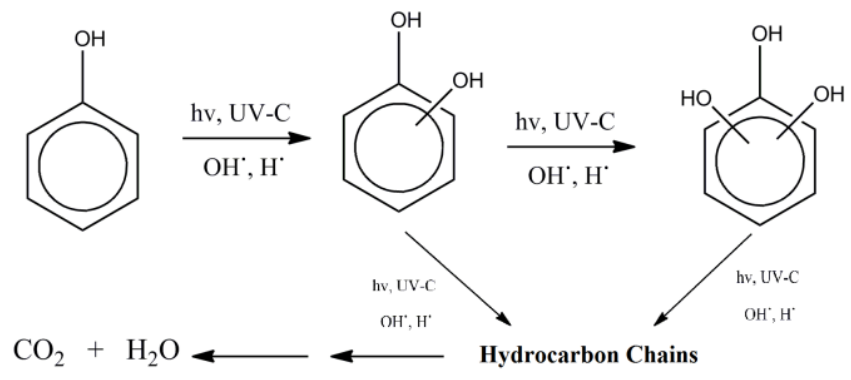

Fig. 5. The possible degradation mechanism of phenol in photocatalysis

In the intermediate phase, phenol can tranform into compounds such as catechol, benzoquinone or resorinone by the addition of $\mathrm{OH}$ group at orthor or para position. As a result, ring-opening reactions subsequently happened leading to the formation of hydrocarbon chains. Due to weak energy of C-H, H-O, C-O, these organic short-chains were oxidized easily to carbon dioxide and water [20]. These are considered as complete mineralization phase of phenol. Therefore, it is recommened that intermediate compounds in phenol photodegradation need to be identified more clearly in the further work.

\section{CONCLUSIONS}

The photocatalytic process using commercial $\mathrm{TiO}_{2}$ powders can remove phenol from water after 24 hours of illumination. The found adequate concentration of $\mathrm{TiO}_{2}$ is 0.9 $\mathrm{g} / \mathrm{L}$ for $100 \mathrm{ppm}$ of phenol solution. Due to the highly-stable structure, phenol was only decomposed by $\mathrm{TiO}_{2}$ catalyst under illumination of UV light. The COD measurement showed that COD value decreased slightly in the first 16 hours of illumination, but it reduced rapidly after that. This occurred similarly to the result of UV-Vis spectrum. Therefore, it can be concluded that the photodegradation of phenol include two phases. In the intermediate phase, by-products were generated from direct oxidation of phenol including aromatic compounds and hydrocarbon chains. Subsequently, these intermediates were completely mineralized to carbon dioxide and water in mineralization phase. Therefore, the investigation of intermediate phases needs to be studied more clearly in the further work.

\section{ACKNOWLEDGMENT}

The authors would like to thank to Siam Kubota Corporation Co., Ltd. and Naresuan University's research funding for the financial support.

\section{REFERENCES}

[1] D. Fabbri, A. B. Prevot, and E. Pramauro, "Effect of surfactant microstructures on photocatalytic degradation of phenol and chlorophenols," Applied Catalysis B: Environmental, vol. 62, pp. 21-27, Jan. 2006.

[2] E. Grabowska, J. Reszczynska, and A. Zaleska, "Mechanism of phenol photodegradation in the presence of pure and modified- $\mathrm{TiO}_{2}$ : A Review,"Water Research, vol. 46, pp. 5453-5471, Nov. 2012.

[3] N. Chaudhary and C. Balomajumder, "Optimization study of adsorption parameters for removal of phenol on aluminum impregnated fly ash using response surface methodology," The Taiwan Institute of Chemical Engineers, vol. 45, pp. 852-859, May 2014

[4] A. Hasanoglu, "Removal of phenol from wastewaters using membrane contactors: Comparative experimental analysis of emulsion pertraction," Desalination, vol. 309, pp. 171-180, Jan. 2013.

[5] J.W. Pattersom, Industrial Wastewater Treatment Technology, $2^{\text {nd }}$ ed. Butterworth: Boston, 1985, pp. 199-215.

[6] S. Vasudevan, "An efficient removal of phenol from water by peroxi-electrocoagulation processes," Water Process Engineering, vol. 2, pp. 53-57, Jun. 2014.

[7] N. Barka, I. Bakas, S. Qourzal, A. and Y. Ait-Ichou, "Degradation of phenol in water by titanium dioxide photocatalysis," Oriental Journal of Chemistry, vol. 29, pp. 1055-1060, 2013.

[8] P. Navarro, J. Sarasa, D. Sierra, S. Esteban, and J. L. Ovelleiro, "Degradation of wine industry wastewaters by photocatalytic advanced oxidation," Water Science Technology, vol. 51, pp. 113-120, 2005.

[9] M. N. Chong, B. Jin, C. W. K. Chow, and C. Saint, "Recent developments in photocatalytic water treatment technology: A review," Water Research, vol. 44, pp. 2997-3027, May 2010.

[10] C. H. Chiou and R. S. Juang, "Photocatalytic degradation of phenol in aqueous solutions by pr-doped $\mathrm{TiO}_{2}$ nanoparticles," Hazardous Materials, vol. 149, pp. 1-7, October 2007.

[11] C. H. Chiou, R. S. Juang, and C.Y. Wu, "Influence of operating parameters on photocatalytic degradation of phenol in $\mathrm{UV} / \mathrm{TiO}_{2}$ process," Chemical Engineering, vol. 139, pp. 322-329, June 2008.

[12] M. Yasmina, K. Mourad, S. H. Mohammed, and C. Khaoula "Treatment heterogeneous photocatalysis; factors influencing the photocatalytic degradation by $\mathrm{TiO}_{2}$," Energy Procedia, vol. 50, pp. 559-566, 2014.

[13] J. M. Herrmann, "Heterogeneous photocatalysis: State of the art and present applications," Topics in Catalysis, vol. 34, pp. 49-65, May 2005.

[14] K. Nakata and A. Fujishima, " $\mathrm{TiO}_{2}$ photocatalysis: Design and applications," Photochemistry and Phobiology C: Photochemistry Reviews, vol. 13, pp. 169-189, Sept. 2012. 
[15] J. Zhou, Y. Zhang, X. S. Zhao, and A. K. Ray, "Photodegradation of Benzoic Acid over Metal-Doped $\mathrm{TiO}_{2}$," Ind. Eng. Chem. Res., vol. 45, Apr. 2006.

[16] R. Thiruvenkatachari, S. Vigneswaran, and I. S. Moon, "A review on $\mathrm{UV} / \mathrm{TiO}_{2}$ photocatalytic oxidation process," Korean J. Chem. Eng., vol. 25, pp. 64-72, 2008.

[17] N. Yuangpho, S. T. T. Le, T. Treerujiraphapong, W. Khanitchaidecha, and A. Nakaruk, "Enhanced photocatalytic performance of $\mathrm{TiO}_{2}$ particles via effect of anatase-rutile ratio," Physica E: Low-Dimensional Systems and Nanostructures, vol. 67, pp. 18-22, March 2015.

[18] M. C. Neves, J. M. F. Nogueira, T. Trindade, M. H. Mendonca, M. I. Pereira, and O. C. Monteiro, "Photosensitization of $\mathrm{TiO}_{2}$ by $\mathrm{Ag}_{2} \mathrm{~S}$ and its catalytic activity on phenol photodegradation," Photochemistry and Photobiology A: Chemistry, vol. 204, pp. 168-173, May 2009.

[19] R. A. Doong and W. H. Chang, "Photodegradation of parathion in aqueous titanium dioxide and zero-valent iron solutions in the presence of hydrogen peroxide," Photochemistry and Photobiology A: Chemistry, vol. 116, pp. 221-228, July 1998.

[20] Z. Guo, R. Ma, and G. Li, "Degradation of phenol by nanomaterial $\mathrm{TiO}_{2}$ in wastewater," Chemical Engineering, vol. 119, pp. 55-59, Jun. 2006.

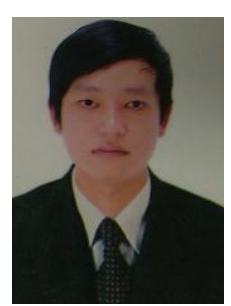

D. T. T. Trinh is currently a postgraduate student studying for master of environmental engineering degree at the Department of Civil Engineering, Naresuan Univesity, Thailand. He graduated with the bachelor degree in environmental management, CanTho University, Vietnam, in 2013. His expertise covers the following areas: modelling in environmental management, $\mathrm{TiO}_{2}$ photocatalytic progresses.

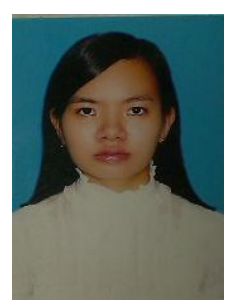

S. T. T. Le is currently a postgraduate student studying for the master of environmental engineering degree at the Department of Civil Engineering, Naresuan Univesity, Thailand. She graduated with her bachelor degree in environmental technology, $\mathrm{Ho} \mathrm{Chi}$ Minh city, University of Science, Vietnam in 2013. Her expertise covers the following areas: Heterogeneous Fenton reaction, $\mathrm{TiO}_{2}$ photocatalysis and their application in water and wastewater

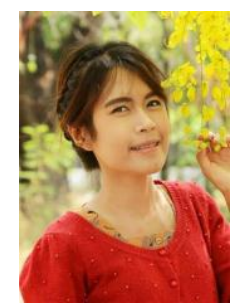

D. Channei graduated with his Ph.D. in chemistry from Chiang Mai Univesity, Thailand in 2015. From 2010 to 2011 she worked at School of Materials Science and Engineering, The University of New South Wale, Australia, under the supervision of Prof C. C. Sorrell as an exchange student. At the present, she is lecturer at Department of Chemistry, Naresuan Unviesity, Thailand. Her research interests include synthesis of metal oxide catalysts, photocatalysis process, and physico-chemical properties of materials.

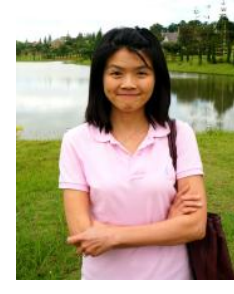

W. Khanitchaidecha graduated with a Ph.D. in environmental engineering from University of Yamanashi, Japan, in 2010. Then, she was appointed as a postdoctoral fellow at the same university until 2012. At the present, she is a lecturer at the Department of Civil Engineering, Naresuan Univesity, Thailand. Her research interest lies in biological process for water treatment, advanced oxidation technology, and water quality assessment.

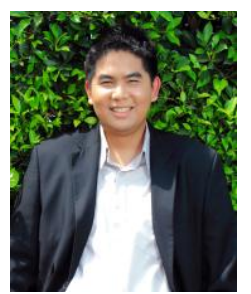

A. Nakaruk graduated with a Ph.D. in materials science and engineering from The University of New South Wales, Australia, in 2010. Then, he worked as a researcher associated at School of Materials Science and Engineering, UNSW until the end of 2012. Since 2013, he has been working as a lecturer at Department of Industrial Engineering, Naresuan University, Thailand. His research interests involves in ceramic processing, thin film technology, photocatalysis process, and materials characterisation.

treatment. 